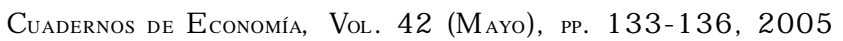

\title{
Symposium on Spatial Inequality in Latin America
}

\author{
RAVI KanBUR \\ Cornell University \\ LuIs F. LóPEZ-CALVA \\ Universidad de las Américas, Puebla \\ Anthony J. Venables \\ London School of Economics
}

Latin America is the region with the highest levels of inequality in the world. This is the case when we look at inequality in income levels and incomegeneration capabilities among individuals, using micro-data. Recently, research has also looked into regional disparities between and within countries, which has raised new and important theoretical and empirical questions. Given the importance of the issue, especially in this region of the world, UNU and WIDER decided to launch a call for papers for a meeting to dicuss recent findings aimed at explaining regional disparities in Latin America and the Caribbean. Three papers published in the previous issue and two in the present issue of Cuadernos de Economía-Latin American Journal of Economics were selected from those presented at a conference held at Universidad de las Américas, Puebla, in Cholula, México, as part of the UNU-WIDER project onSpatial Disparities in Human Development (Wood You, and Zhang (2004), Soto and Torche (2004), Araujo (2004), Escobal and Torero (2005), García-Verdú (2005)). The project included the analysis of different regions and countries and was motivated by the presence of wide spatial disparities in per capita income and other socio-economic indicators within the Latin American region. More than 25 papers were received for the conference, whereas 8 were selected for a more detailed refereeing process and 5 have been selected for publication in this journal.

The papers present interesting and innovative empirical and methodological issues. Given the characteristics of the region, the analysis of the rural-urban dichotomy becomes relevant, as it plays a central role in understanding regional development patterns. The paper by Wood, You and Zhang document the changes in spatial patterns of crop yield in Latin America and the Caribbean and show that yield levels across the region do not appear to have converged over the period 1975-1998. Moreover, it delves into why spatial variations persist, using geographic information system tools and inequality decomposition methods. In order to explain the observed patterns of yield variability, three hypotheses are proposed. The first is that agricultural $R \& D$ in the past decades has been biased toward generating technologies for use in more favorable production environments. Complex aspects 
of agro-ecological specificity may inhibit technological spillover to less-favored production areas, and therefore reduce potential payoffs to research investment. The second hypothesis is related to weather variability. Agricultural production systems are location specific and a contributing factor to the spatial differences among yields is the relative resource endowment among locations, particularly for low-input production systems. When plotting regional variability in annual rainfall and the yields of rice and maize, rainfall is more variable than yield, and aggregate rice yields are more variable than maize yields. There is also a small downward trend in annual rainfall. In the case of rice, the association between rice yield and rainfall variability is weak, while the association between yield and rainfall variability appears to be much stronger for maize. The finding of a downward trend in rainfall over the period 1975-1995 supports the idea that changing weather patterns may have contributed to increasing yield divergence, since drier conditions are associated with lower yields in rain-fed systems. Finally, agricultural production technologies generated in one country often spillover to other countries with similar agro-ecological conditions if regional or local capacity to adapt and disseminate the technologies that are available. The difference in research capacity and institutions and human resource endowment may create barriers to countryto-country spillovers.

One of the most important variables to explain regional disparities and migration patterns has to do with non-agricultural rural activities. Thus, several recent studies have addressed the importance of off-farm incomes in rural areas of the developing world. The heterogeneity in the types of occupations suggests that the non-agricultural sector explains the wide variation in terms of wages, working conditions, stability and contracts. Araujo focuses on the impact of nonagricultural rural employment (NARE) on poverty. This paper also explores in which environments policy interventions in education and roads are potentially more effective in reducing poverty through NARE. The paper shows a robust negative effect of manufacturing and services employment on poverty and spatial inequality. When exploring the effectiveness of policy interventions in reducing poverty, the results suggest that interventions to improve roads and secondary education reduce poverty through services employment in rural and semi urban municipalities and through manufacturing employment only in semi urban municipalities. The data used to characterize poverty comes from Mexican 1990 and 2000 population census. Poverty, Araujo shows, is also higher in municipalities with higher income inequality, and with lower government expenditures. Higher values of agricultural output are negatively related to poverty and this effect is larger in rural than in semi urban municipalities. An important finding is that the effectiveness of secondary education in reducing poverty differs across rural and semi urban municipalities in terms of inequality. While these interventions are more poverty-reducing in rural municipalities with low income inequality, the opposite is true for semi urban ones.

On a similar line of analysis, Escobal and Torero evaluate, using household and communal level surveys in rural Peru, the differential impact on poverty of different types of asset investments. This study considers three types of public 
goods and services, a) traditional infrastructure, b) human capital generating public services and c) information and communication technologies. It also looks at the interaction effects on poverty between the traditional infrastructure and those that generate network externalities. The paper is based on recent literature, which argues that geography has a causal role in determining how household welfare evolves and this could explain why poor households cannot escape out of poverty. The hypothesis by the authors is that what seems to be geographic differences in living standards in Peru can be almost fully explained when spatial concentration of households is taken into account with observable non-geographical characteristics like public and private assets. The fact that geography has no additional impact on regional per-capita expenditure differences has to do with the fact that key infrastructure variables such as school, access to electricity, water and sanitation have dampened the effect of geography on regional expenditure differentials. The main result suggests that a poverty trap linked to adverse geographic conditions may be overcome with an adequate provision of private and public assets. An innovative methodology looks at the complementarity in access to assets. The paper shows a positive effect on per-capita expenditure and poverty of being able to access to more than one asset at the same time. In this sense access or ownership of a combination of two or more assets tends to have a higher welfare impact than the sum of the individual impacts. The results also show that the additional provision of public goods serves as an equalizing force between the rural poor and the non poor.

Moving into a more general view of regional inequalities within countries, Soto and Torche analyze the evolution of regional disparities in Chile. The case is important given that, in the past 20 years, Chile has pursued an aggressive strategy of market liberalization, trade opening and other structural transformations, and the literature suggests that growth has not benefited regions equally, while income inequality did not decline and welfare differentials showed high persistence. The paper documents that per capita income and productivity levels either do not seem to be converging towards a common long-run level or the speed of convergence is too slow. Among regions in Chile, poverty and income inequality evolved in dissimilar ways. As expected, in all regions poverty levels declined, but some regions benefited the most while others improved less substantially. Within-region income inequality (measured by Gini indices) remained virtually stagnant in several regions, improved notoriously in other regions and worsened clearly in some others. The authors use a panel conformed by creating five non-overlapping subsamples of 5-year each, covering the entire period of 1975 to 2000 in order to analyze convergence patterns. The results show a negative sign for conditional convergence and that speed of convergence ranges between $3.3 \%$ and $4.8 \%$ on an annual basis. By including unemployment as a proxy for the business cycle, a negative parameter indicates that regions in the lower part of their activity cycle (recession) tend to grow faster than those in booms. In summary, convergence, if it exists is quite slow. The main hypothesis stated by the authors is that lack of convergence in Chile seems to be largely associated with low levels of regional migration and this might be caused by housing policies. 
Finally, García-Verdú analyzes the dynamics of the distributions of per capita Gross Domestic Product (GDP), the infant mortality rate, and the adult literacy rate across states in Mexico during the period 1940-2000. It also analyzes the hypothesis of convergence to a common level of per capita GDP, infant mortality, and adult literacy among states. Mexico is a country where trade liberalization and the implementation of the North American Free Trade Agreement have resulted in an increasing regional polarization and has implied the reversion of a regional convergence pattern in the last two decades. The approach used by García-Verdú exploits both the time-series and cross-section dimensions of the data by tracking the evolution over time of the entire cross-section distributions through the estimation of transition matrices and kernel density estimates for each of these welfare indicators. The paper shows that there is high persistence over time in the positions states occupy in the distribution of these welfare indicators. The convergence process has indeed taken place in specific welfare indicators in a stronger fashion, indicators such as adult literacy. Such convergence does not seem to have taken place in variables like per capita GDP or infant mortality among Mexican states.

PAPERS:

"Spatial Patterns of Crop Yields in Latin America and the Caribbean". Wood, S., You, L., Zhang, X. (2004).

"Spatial Inequality, Migration and Economic Growth in Chile".

Soto, R. and Torche, A. (2004).

"Can Non-Agricultural Employment Reduce Rural Poverty? Evidence from Mexico". Araujo, C. (2004).

"Measuring the Impact of Asset Complementarities: the Case of Rural Peru". Escobal, J. and Torero, M. (2005).

"Income, Mortality, and Literacy Distribution Dynamics across States in Mexico: 1940-2000".

R. García-Verdú (2005). 